\title{
Acute Effect of a Session of Resistance Exercises Using the 80\% 1RM Circuit Method on Blood Pressure
}

\author{
Rodrigo Poderoso de Souza ${ }^{* 1,2}$ and Ana Carolina Gleden Mighty ${ }^{1}$ \\ ${ }^{1}$ University of Northern Paraná - Unopar Cascavel - Paraná, Portugal \\ ${ }^{2}$ University Brings them Montes and Alto Douro, UTAD - Portugal
}

*Corresponding author: Rodrigo Poderoso de Souza, Department of Sports Sciences, University of Northern Paraná - Unopar

Cascavel - Paraná, Portugal

\section{ARTICLE INFO}

Received: 橎 June 06, 2020

Published: 幽 June 25, 2020

Citation: Rodrigo Poderoso de Souza, Ana Carolina Gleden Mighty. Acute Effect of a Session of Resistance Exercises Using the $80 \%$ 1RM Circuit Method on Blood Pressure. Biomed J Sci \& Tech Res 28(3)2020. BJSTR. MS.ID.004660.

Keywords: Blood Pressure; Resistance Training; Exercise

Abbreviations: SBP: Systolic Blood Pressure; DBP: Diastolic Blood Pressure; ACSM: American College of Sports Medicine

\section{ABSTRACT}

Currently, the literature has recommended the use of resistance physical exercises to control blood pressure, due to evidence that it has been shown to be safe and effective to the practitioner, being an important alternative of non-drug treatment for hypertensive individuals. As a result, it is necessary to investigate the behavior of blood pressure before such exercises to ensure the efficiency of the same without offering risks to the practitioner.

Objective: to compare the behavior of blood pressure after a resistance exercise session in the circuit method, using a load of $80 \%$ of a maximum repetition - 1RM with the pre-exercise situation.

Methodology: The study sample consisted of 12 normotensive male volunteers aged $24,09 \pm 2.43$ years, body mass $71.68 \pm 5.18 \mathrm{~kg}$, height of $1.73 \pm 0.04 \mathrm{~cm}$, BMI of $23.83 \pm 1.60 \mathrm{~kg} / \mathrm{m} 2$ and fat $16.84 \pm 2.99$. The volunteers attended the bodybuilding laboratory during two experimental sessions on alternate days for: 1 - determination of the maximum load (1-RM) in six exercises (extensor chair, bench press straight in the machine, leg press, pulled on the machine, flexor chair and rowing machine); 2nd - an experimental session with 3 resistance exercise circuits at high intensity (08 repetitions/exercise x $80 \% 1-\mathrm{RM}$ ). The variables measured at rest and immediately after the experimental session were systolic blood pressure (SBP) and diastolic blood pressure (DBP). The data were analyzed based on descriptive statistics, with values of mean and standard deviation. For the comparison of blood pressure before and immediately after the measurements obtained, the Student " $\mathrm{t}$ " test was used for dependent samples. All procedures were performed in the Statistic for Windows 6.0 Software and the level of significance adopted was $\mathrm{p}<0.05$.

Results: According to the results, it was observed that systolic blood pressure immediately after the exercise session was significantly higher than that observed at rest. However, no difference was observed in diastolic blood pressure values.

Conclusion: Thus, it is concluded that the resistance exercise at $80 \%$ of $1 \mathrm{RM}$ in the circuit method causes a significant increase in SBP immediately after its execution. It is suggested to carry out future studies that follow the recovery period after exertion, in order to verify if there would be any hypotensive effect for the practitioner.

\section{Introduction}

According to the Brazilian Society of Arterial Hypertension (2008), there are 600 million hypertensive patients in the world, and it also states that the prevalence of hypertension in Brazil is high, because among adults, $30 \%$ to $35 \%$ have the disease. As a consequence of this increase in blood pressure levels, the target organs are exposed to serious risks of commitment to increased cardiovascular risk. This increase in blood pressure may have as causes sedentary lifestyle, stress, inadequate eating habits and alcohol and tobacco consumption, which are characteristics derived from the urbanized and post-technology established lifestyle [1]. In 
view of this reality, it becomes evident the need for interventional approaches in an attempt to prevent and treat hypertension [2]. To achieve these objectives, it has been widely recommended by health professionals, along with pharmacological treatment, adherence to a healthy way of life and regular practice of physical exercises, as effective ways to slow down blood pressure levels [3]. Numerous studies prove the benefits that are offered by physical exercises, both in the prevention and treatment of this disease. Because they are characterized by a situation that removes the organism from its homeostasis, causing several physiological adaptations that are necessary and, among them, those related to cardiovascular function during the ex-ercício [4].

Currently, resistance physical exercises have been used in programs that promote, when adequately supervised, significant benefits and low risks to the practitioner, contributing to the reduction of resting rial art pressure (Bermudes, 2004). Doederlein, et al. [5] indicate that a safe method for conducting a training is by giving additional elements to the manipulation of variables adjunct to their absolute and relative intensity (type of exercise, recovery interval, number of repetitions and sets, mobilized load and execution speed). However, some studies have shown that the intensity of exertion does not influence the hypotensive response after exercise [6] and on the other hand, other investigations have shown that the intensity of exercise can influence the size and duration of the blood pressure response [7]. According to the authors, the physical quality involved in this type of physical activity is muscle strength, which, in addition to being necessary in development, is, in terms of health promotion, a fundamental parameter for the practice of occupational and leisure activities, contributing to the self-sufficiency of sedentary individuals, the elderly, hypertensives and ardiopaths (Bermudes, 2004).

For a broader discussion on the effects of exercise on blood pressure, it is worth noting that it can be influenced not only by the adaptations resulting from chronic physical training (chronic adaptations), but also by the influence of a single exercise session (subacute or post-exercise effects) [8]. In a study conducted by Cornelissen, et al. [9], composed of 12 analyses and 341 volunteers, a reduction in systolic blood pressure and diastolic blood pressure values was demonstrated for individuals who were exposed to resistance training. The same study describes that no differences were observed related to exercise intensities, as well as the use of conventional or circuit resistance training. Since, in conventional training, all the series of a given exercise are performed before starting the next one and, generally, there are higher loads and interval time than in the circuit method, where it is more continuous and with shorter interval time, since the execution is a single series in each station, passing the next exercise immediately, and repeating the circuit more often if necessary. Although resistance training, similarly to aerobic training [10], causes only minimal decreases in blood pressure levels, in population terms this consequence may have an impact on a lower incidence of coronary artery disease and stroke [11]. Thus, the present study aims to compare the behavior of blood pressure after a resistance exercise session in the circuit method, using a load of $80 \%$ of one the maximum repetition - 1RM with the pre-exercise situation.

\section{Methodology}

The study included 12 normotensive male volunteers, aged 24.9 \pm 2.43 years, practicing resistance exercises for at least six months and practicing these activities at least three times a week. Exclusion criteria were the use of anabolic steroids and medications that could interfere with the behavior of blood pressure, as well as the withdrawal of the volunteer at the time and the intake of caffeine, cola-based soft drinks, chocolates and smoking on the day of the test. Data collection was performed in three days, with a minimum interval of 48 hours between each session. On the first day, all volunteers were submitted to the PAR-Q [12] for physical readiness evaluation, signed a free and informed consent form, according to resolution 196/96 of the Brazilian National Health Council, and before the present study, it was approved by the ethics committee of the Assis Gurgacz College (OPINION 187/2008). Evaluations of anthropometric and body composition variables (weight, height, and skinfolds) were also performed, as well as a maximal load test in the exercises involved in the study.

Aiming to mitigate the possibility of occurrence of errors during the tests of a maximum repetition (1RM), the following measures were taken: The instructions on the entire routine of the tests were passed in advance to all the components of the sample; The volunteer was instructed on the execution technique; The evaluator was attentive at all times of the executions, in order to avoid that the evaluated would make mistakes that could compromise the result of the collection of data; The tests were scheduled in advance and always performed at the same time for each subject. Body mass was measured using a Toledo digital scale, and height was measured using a Sanny wall stadiometer, in agreement with the procedures described by Gordon, Chumlea and Roche (1988). Body adiposity was determined by using a Lange scientific adipometer (Cambridge Scientific Industries Inc., Cambridge, Maryland). The thickness of the subscapular, abdominal and triceps skinfolds of ac ordo were measured with the procedures described by Harrison, Bursik, Carter, Johnston, Lohman and Pollock (1988). The fat percentage was determined through a three-fold protocol (Guedes, 2003). It is noteworthy that the measurement error will be at $\max \pm 1.0 \mathrm{~mm}$ and the test-retest coefficient of $>0.95$. On the second day, the volunteers participated in the experimental session of resistance exercise, being $80 \%$ of the maximum load in the circuit method. The resistance training was applied with the load of $80 \%$ of $1 \mathrm{RM}$, in three circuits, and performed in six devices: extension chair, bench press straight in the machine, leg press, machine pull, flexor chair and rowing machine. 
In this same order, they performed a total of eight repetitions, two seconds of execution for each phase (excentric and concentric), sixty seconds of recovery between each device and one hundred and twenty seconds of interval between each circuit. It is noteworthy that considering the number of exercises, number of repetitions, execution time of each movement, recovery time between each exercise, as well as the recovery time between each circuit, the volume of the exercise session was similar in both experimental situations. BP measurement was performed using the Oscillomé trica Measurement Method, using an Automatic Digital Blood Pressure Monitor, BP 3BTO-A models manufactured by Micro life being verified after 05,10 and 15 minutes of rest, and immediately after the session of resistance exercises. All data were analyzed bydescriptive statistics, with mean and standard deviation values. For the comparison of blood pressure before and immediately

Table 1: General characteristics of the sample. after the measurements obtained, the Student " $t$ " test was used for dependent samples. All procedures were performed in the Statistic for Windows 6.0 Software and the level of significance adopted was $\mathrm{p}<0.05$.

\section{Results}

Table 1 presents the general characteristics of the sample, with mean values and standard deviation of age (Table 1). Table 2 shows the results of the " $t$ " test to compare the mean values $( \pm$ standard deviation) for systolic and diastolic blood pressure at rest and immediately after a resistance exercise session in the $80 \%$ 1RM circuit method. According to the results, it was observed that systolic blood pressure after the exercise session was significantly higher than that observed at rest. However, no difference was observed in diastolic blood pressure values immediately after exercise (Table 2).

\begin{tabular}{|c|c|c|}
\hline Variables & Average & Standard Deviation \\
\hline Age (years) & 24,9 & 2,43 \\
\hline Body mass (kg) & 71,68 & 5,18 \\
\hline Height (cm) & 1,73 & 0,04 \\
\hline IMC (kg/m2) & 23,83 & 1,60 \\
\hline$\%$ fat (\%) & 16,84 & 2,99 \\
\hline
\end{tabular}

Table 2: T-test forco-comparison of mean values ( \pm standard deviation) for systolic and diastolic blood pressure at rest and immediately after a resistance exercise session in the $80 \% 1 \mathrm{RM}$ circuit method.

\begin{tabular}{|c|c|c|c|c|}
\hline & Pre-Exercise & Post-Exercise & t & p \\
\hline NOT (mmHg) & $107,92 \pm 8,61$ & $144,25 \pm 36,32$ & $-3,145$ & $0,00^{*}$ \\
\hline PAD (mmHg) & $74,06 \pm 8,05$ & $87,75 \pm 36,12$ & $-1,244$ & 0,23 \\
\hline
\end{tabular}

SBP: Systolic Blood Pressure; Diastolic Blood Pressure; mmHg: Millimeters of Mercury

${ }^{*} \mathrm{p}<0,05$

\section{Discussion}

The present study compared the blood pressure condition before and immediately after a session of resistance physical exercise in the circuit method with $80 \%$ of $1 \mathrm{RM}$. According to the results of the research, it was observed that immediately after exercise the mean systolic blood pressure was significantly higher than the means preceding exercise. This result is explained in part by the activation of chemoreceptors due to peripheral fatigue [13]. Considering that the $80 \%$ load of $1 \mathrm{RM}$ can be classified as a high intensity, these results corroborate the literature, which indicate that exercises performed until exhaustion would result in a higher blood pressure response immediately after exertion [14]. However, it should be considered that the results of the present study are limited to comparing resting blood pressure and immediately after exercise. The literature also points out the acute benefit in blood pressure control in normotensive individuals [6]. The decrease in blood pressure levels after resistance exercise is proven by the highlights of other recent autores, which conducted studies in normotensive and hypertensive patients of different age groups
[15,16] (Brown, 1994; MacDonald, 2000; Lizardo, I'm not Simões, 2005).

However, in a study conducted by Fisher (1999), no postexercise hypotension was observed for diastolic blood pressure from resistance exercise performed at 50\% of 1RM in normotensive and hypertensive patients. Although it was not the focus of this study, the monitoring of blood pressure after resistance exercise could show a hypotensive effect. Therefore, according to Hara and Floras (1994) hypotension after exercise of diastolic blood pressure could occur because it is related to the reduction of peripheral vascular resistance from vasod there being maintained after exercise, which occurs, among other reasons, due to the marked production of metabolites, and also according to Mota [16], resistance exercise sessions provide greater post-exercise metabolic stress due to the higher peak of healthy lactate.guíneo. On the other hand, during strength exercise, both systolic and diastolic blood pressure tend to rise, also promoting a significant increase in mean blood pressure, even for a short period of time (MacDougal et al. [17] cited by Polito; Farinatti [18]). 
The American College of Sports Medicine (ACSM) [19] mentions that, in isolation, SBP and DBP show different behaviors during exercise. SBP tends to increase in direct proportion to the intensity of the exercise due to the increase in cardiac output, which justifies the result of the present study. However, the results obtained contradict the study by Franklin, et al. [20], who claim that there is a significant increase in DBP. Corroborating the nonoccurrence of significant alteration of DBP, it may be due to the fact that the volunteers of the present study are young normotensive, with experience and regular practice of resistance exercise. The literature points out that the regular practice of weight training can slow down acute responses to absolute load values, on the other hand, when taking into account their relative values, both blood pressure and heart rate tend not to change or even the increase, mainly in maximum request efforts [18].

Among the most important chronic adaptations resulting from the regular practice of strength exercises, the possible reduction of the frequency of the dyad deficit [21] and resting blood pressure [22] can be cited [22], and also the least cardiac overload during exercise, with lower double-product associated [23]. Still talking about the adaptations caused, Fleck (1999) points out that blood pressure increases proportionally in relation to load and increases in relation to muscle mass involved in exercise. This response does not seem to be linear, thus indicating that the circulatory responses to the resistance exercise are largely determined by the intensity of the effort, performed for each person during the completion of an equal number of repetitions. Referring to the prescription of strength exercise, the ACSM [19] suggests for patients with cardiovascular involvement a satisfactory number of repetitions between 10 and 15, of submáximo character and with subjective feeling of effort between 11 and 15 (Borg Scale), depending on the state of training and level of illness [24-27].

When it comes to the training volume, it is two to five times a week. For Santarém (2001), the effectiveness of training requires relatively high weights with few repetitions, provided that no maximum effort is made, blood pressure increases within safe levels, which is in ac line with the objective proposed by the present study, where a higher load of $80 \%$ of 1RM was used in a circuit method. The author adds that it is wrong to say that light weights and a greater number of repetitions are safer, because when isometry and nea occur, at the end of the series blood pressure would increase more than with greater weight and fewer repetitions. There is a lot of evidence and studies that point to resistance training as beneficial and safe even for people with heart disease, provided that it is prescribed with the care necessarily considered [28-30].

\section{Conclusion}

According to the results, it is concluded that the exercise resisted at $80 \%$ of $1 \mathrm{RM}$ in the circuit method, causes a significant increase in SBP immediately after its execution. It is suggested to carry out future studies that follow the recovery period after exertion, in order to verify if there would be any hypotensive effect for the practitioner, as well as to apply resistance exercise in the prevention and non-pharmacological treatment of arterial hypertension.

\section{References}

1. (2002) IV Brazilian Guidelines on Arterial Hypertension.

2. Laterza MC, Rondon MUPB, Negrão CE (2007) Antihypertensive effect of exercise. Brazilian Journal of Hypertension pp. 104-111.

3. Pescatello LS, Franklin BA, Fagard R, Fargulhar WB, Kelley GA, et al. (2004) American College of Sports Medicine. Exercise and hypertension. Med Sci Sports Exercise 36(3): 533-553.

4. Brum PC, Forjaz CLM, Tinucci T, Negrão CE (2004) Acute adaptations and chronicles of physical exercise in the cardiovascular system. Paulista Magazine of Physical Education 18: 21-31.

5. Doederlein M, Farinati PTV (2003) Considerations on blood pressure measurement in exercise against resistance. Brazilian Journal of Sports Medicine 9(1): 25-33.

6. Forjaz CLM, Matsudaira Y, Rogrigues FB, Nunes N, Negrão CS (1998) Post-exercise changes in blood pressure, heart rate and rate pressure product at different exercise intensities in normotensive humans. Braz J Med Biol Res 31(10): 1247-1255.

7. Polito MD, Simão R, Senna GW, Farinatti PTV (2003) Hypotensive effect of strength exercise performed at different intensities and same workload. Brazilian Journal of Sports Medicine 9(2): 69-73.

8. Umpierre D, Stein R (2007) Hemodynamic and vascular effects of resistance training: implications for cardiovascular disease. Brazilian Archives of Cardiology 89(4): 256-262.

9. Cornelissen VA, Fagard RH (2005) Effect of resistance training on resting blood pressure: a meta-analysis of randomized controlled trials. J Hypertens 23(2): 251-259.

10. Whelton SP, Chin A, Xin X, He J (2002) Effect of resistance training on resting blood pressure: a meta-analysis of randomized controlled trials. Ann Intern Med 134: 1-11.

11. Whelton PK, He J, Appel LJ, Cutler JA, Havas S, et al. (2002) Primary prevention of hypertension: clinical and public health advisory from the National High Blood Pressure Education Program. JAMA 288(15): 18821888.

12. Shepard RJ (1988) PAR-Q Canadian home fitness test and exercise screening alternatives. Sports Medicine 5(3): 185-195.

13. Carrington CA, Whyte MJ (2001) Exercise-induced muscle chemoreflex modulation of spontaneous baroreflex sensitivity in man. J Physiol 536(Pt 3): 957-962.

14. Letini AC, Mckelvie RS, Mccartney N, Tomlinson CW, Macdougall JD (1993) Left ventricular response in healthy Young men during heavyintensity weight lifting exercise. J Appl Physiol 75(6): 2703-2710.

15. Focht BC, Koltyn KF (1999) Influence of resistance exercise of different intensities on state anxiety and blood pressure. Med Sci Sports Exercises 31(3): 456-463.

16. Mota MR, Pardono E, Borges RF, Ferreira AP, Simões HG, et al. (2008) Effect of the type of exercise on post-exercise hypotension in normotensive individuals. Digital magazine - Buenos Aires 5(1).

17. Macdougall JD, Tuxen D, Sale DG, Moroz JR, Sutton JR (1985) Arterial blood pressure response to heavy resistance exercise. J Appl Physiol 58(3): 785-790.

18. Polito MD, Farinatti PTV (2003) Heart rate responses, prepare arterial and double product to exercise against resistance: a review of the literature. Portuguese Journal of Sports Sciences 3(1): 79-91. 
19. (2000) American College of Sports Medicine, ACSM's Guidelines for Exercise Testing and Prescription 20(4): 251-258.

20. Franklin BA, Bonzheim K, Gordon S, Timmis GC (1991) Resistamce training in cardiac reabilitation. J Cardiopul Rehabil 11: 99-107.

21. Goldberg L, Elliot DL, Kuehl KS (1994) A comparison of the cardiovascular effects of running and wheigth training. J Strength Cond Res pp. 219-224.

22. Kelley GA, Kelley KS (2000) Progressive resistance exercise and resting blood pressure: a meta-analysis of randomized controlled trials Hypertension 35(3): 838-843.

23. Maiorana A, O’Driscoll G, Cheethan C, Collis J, Goodman C, et al. (1985) Combined aerobic and resistance exercise training improves functional capacity and strength in CHF. J Appl Physiol 88(5): 1565-1570.

24. Morrissey MC, Harman EA, Johnson MJ (1995) Resistance training modes: specificity and effectiveness. Med Sci Sports Exerc 27(5): 648660.

ISSN: 2574-1241

DOI: 10.26717/BJSTR.2020.28.004660

Rodrigo Poderoso de Souza. Biomed J Sci \& Tech Res

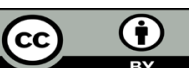

This work is licensed under Creative Commons Attribution 4.0 License

Submission Link: https://biomedres.us/submit-manuscript.php
25. Rondon MUPB (1999) Immediate and prolonged behavior of postexercise blood pressure in normotensive and hypertensive elderly. Doctoral dissertation. São Paulo : EEFE USP.

26. Sale DG, Moroz DE, Mc Kelvie RS, Mac Dougall JD, Mc Cartney N (1994) Effect of training on the blood pressure response to weightlifting. Can J Appl Physiol 19(1): 60-74.

27. (2007) V Brazilian Guidelines in Arterial Hypertension. Arq Bras Cardiol 89(3): e24-79.

28. (2008) Brazilian Society of Hypertension.

29. Tumerelo S, Júnior MFS, Nunes NCR (2003) Influence of age on blood pressure and resting heart rate values. Digital Magazine - Buenos Aires.

30. Verril DE, Ribisl PM (1996) Resistive exercise training in cardiac rehabilitation: An update. Sports Med 21(5): 347-383.

$\begin{array}{ll}\text { BIOMEDICAL } & \text { Assets of Publishing with us } \\ \text { RESEARCHES } & \text { - Global archiving of articles } \\ \text { - Immediate, unrestricted online access } & \text { - Rigorous Peer Review Process } \\ & \text { - Authors Retain Copyrights } \\ \end{array}$

